\title{
The socio-materiality of learning practices and implications for the field of learning technology
}

Aditya Johri*

Department of Engineering Education, Virginia Tech, Blacksburg, Virginia, USA

(Received 31 January 2011; final version received 12 September 2011)

\begin{abstract}
Although the use of digital information technologies in education has become commonplace, there are few, if any, central guiding frameworks or theories that explicate the relationship between technology and learning practices. In this paper, I argue that such a theoretical framework can assist scholars and practitioners alike by working as a conduit to study and design learning technologies. Towards this goal, I propose socio-materiality as a key theoretical construct with valuable insights and implications for the field of learning technology. Sociomateriality helps balance the disproportionate attention given to either the social implications of technology use or the material aspects of technology design. Furthermore, I forward 'socio-material bricolage' as a useful analytical framework to examine and design technology-infused learning environments. I illustrate the value of the framework by applying it to three case studies of formal and informal technology-based learning.
\end{abstract}

Keywords: learning technology; socio-materiality; theoretical framework

\section{Introduction}

On the basis of experimentation to date, it appears that when schools and colleges have learned to capitalize on the full potential of the medium, students at all levels will receive a far broader, deeper, and richer education than has been possible heretofore. (Scanlon 1959, 420)

In the quote above, Scanlon is referring to television as the medium with the potential to solve most problems plaguing education when it was first introduced. This quote encapsulates the euphoria that often accompanies a new technological innovation and its application in education. The quote also captures a core assumption about what it takes to improve education - increased access to content. This viewpoint highlights a consistent conundrum with which the educational enterprise struggles - how to impart maximum learning with minimal use of resources. This effort to improve the efficiency of delivery has been the primary motivation behind educational efforts for decades (Callahan 1962). Within this accepted discourse of efficiency, the solution to educational problems is invariably the application of some form of technology to improve productivity while reducing costs. Not surprisingly, the use of technology often fails to meet the lofted goals that it is purported to achieve. And even if technology succeeds in reducing costs, there is scant evidence that it improves learning.

*Email: ajohri@vt.edu 
There are two major problems with adopting an efficiency orientation with regard to its usefulness for learning technology. First, it forces an inherent technological determinism. Technology is either a replacement or a substitute for an already existing function within the education process. Second, there is an empirical determinism in how to evaluate the role of new technologies in education. This determinism is a result of simplistic notions of technology as a vehicle for efficiency, and invariably emerges from a larger focus on education per se rather than on learning. In this paper I argue that a better understanding of the role of technology in learning can be achieved by adopting a stronger theoretical position to help shift the discourse on learning technology beyond technological deterministic or sociological deterministic accounts. I further argue that empirically adopting an interpretive stance that examines technology-in-practice will allow us to understand the meaning users attach to technology and the meaning technology achieves through enactment in practice (Orlikowski 2002). In order to accomplish these twin goals I propose building a theoretical account of learning technology around the perspective of socio-materiality (Latour 2005; Orlikowski 2010; Orlikowski and Scott 2008; Suchman 2007). Furthermore, I advance socio-material bricolage (Johri 2011a) as an analytical framework that can assist in research and design of learning technology by providing a pertinent lens to examine emergent socially and materially intertwined learning practices.

The use of technology within education, defined broadly, is not a recent phenomenon, but the advent of digital information technology has dramatically changed the landscape of learning technologies and learning practices. From devices such as electronic whiteboards, laptops, and mobile phones, to web-based tools such as the Internet, online gaming, and social networking, the infrastructure of learning has become increasingly digitised. This infrastructure is being used to manage content, to facilitate interaction among students and teachers in distant locations, to undertake functions such as grading, and to conduct research. The future is predicted to be even more digitised with the emergence of electronic books, augmented reality, game-based learning, and gesture-based computing (Johnson et al. 2011). In the current technology-infused environment, students and teachers alike are spending more time with and around digital devices and services. According to Nielsen (2010), time spent on social media worldwide has increased $82 \%$ over the previous year and users spend an average of over five hours on social media. The popularity of electronic games continues to increase exponentially, and according to the Entertainment Software Association (ESA 2010) almost 70\% of American households now play computer or video games. This technology-pervasive landscape calls for a reflective inquiry into the nature and role of technology in learning as our dependence on information technology for socio-cognitive needs is greater than ever and there has never been a more opportune time to shape learning through technology.

\section{Towards theoretical development}

Theory thus become instruments, not answers to enigmas, in which we can rest. We don't lie back upon them, we move forward, and, on occasion, make nature over again by their aid. (James 1907, 46)

Even though scholars and practitioners might now make their theoretical stance explicit, implicitly there is always theory involved in what we study, design or use. The purposes of making theory explicit are many and to make the case for 
theoretical grounding of empirical work, I outline four constructive dimensions (adopted from Johri 2010). First, theory situates our findings or ideas in an existing scholarly conversation and shows clearly how our findings or arguments build upon or transcend prior work. Second, theory helps us provide succinct and coherent explanations for real-world behaviour. The usefulness of theory is its interpretative function. Through it we contextualise the world around us and our actions in the world. Third, theory guides us in constructing knowledge right from the very beginning of a research endeavour by shaping the design of the study itself. A theoretical foundation for data collection and analysis helps avoid repetition and leads to creative outcomes that can help build and grow a body of knowledge. Fourth, theory assists us in the diffusion of research results by providing a guiding framework, a narrative structure, a discourse, or a schema, to assist us in talking about our work and its usefulness. Keeping these advantages of theory in mind, it is easy to see how adopting a theoretical lens can assist scholars and practitioners. Before connecting technology and learning within a specific theoretical paradigm, it is important to situate the conception of learning adopted in this paper. The theoretical and empirical power of sociomateriality, the theoretical approach advanced here, comes from the crucial concept of practice.

\section{Practice-based studies of learning}

A conventional view of learning that focuses predominantly on outcomes and views education as an output of pre-determined tasks executed without any ambiguity overlooks the continuous flow of activities that together encompass learning. Together, these activities can be said to comprise learning practices. The "practice turn" (Bourdieu 1990; de Certeau 1984; also see Schatzki 2001) examines the everyday aspects of life and advocates a stronger focus on people, routines, and situated activity. Given its tacit aspects, practice-based knowledge is produced continuously in situated action, as people draw on their physical presence in a social setting, on their cultural background and experience, and on sentient and sensory information (Blackler 1995; Tyre and von Hippel 1997; Orlikowski 2002). Feldman and Orlikowski (2011) outline the following characteristics of a practice-lens within the context of organising: empirically, a practice-lens focuses on the everyday activity of organising; theoretically, it attempts to articulate relationships that can explain the dynamics of everyday activity, including their generation and operation across contexts and time; philosophically, it is important to focus on everyday activity because practices are the primary building blocks of social reality. Furthermore, Feldman and Orlikowski (2011) argue that, in the practice theory framework, situated actions produce social life and dualisms are rejected in theorising as relations are mutually constitutive.

Learning sciences scholars (see Johri and Olds 2011) have not only adopted a practice-lens but have been instrumental in making 'everyday practices' a central part of social sciences research, particularly since its introduction to the field by Lave's (1988) examination of cognition in informal learning settings. A practice perspective on learning, according to Brown and Duguid (2001), emphasises doing or 'know-how', defined as the ability to put 'know-what' into practice. To achieve 'know-how', it is not enough to just know about something but it is essential to tap into the knowledge of a community to understand application. Therefore, practice- 
based knowledge perspective essentially privileges the collective since no person can know all the heuristics or principles involved or possess all necessary experience (Cook and Brown 1999). Competent practitioners, in a practice-view of learning, know how to interact, negotiate access and participate in the community (Wenger 1998). Learning occurs in activity (Greeno 2006) and is a "shared embodied know-how" (Schatzki 2001, 3); in other words, studies of practice focus on the ways in which participants enact activities with and in relation to each other - often in the same physical setting - in order to accomplish their goals. Overall, research employing the tradition of practice theory shares a commitment to understand learning in terms of human activity; a commitment necessary for socio-material theorising of learning.

\section{Socio-materiality as a theoretical concept}

I propose socio-materiality as a key theoretical perspective that can be leveraged to advance research, design and use of learning technologies in the practice tradition. Within the socio-material tradition, several theories have been advanced by scholars including actor-network theory (Latour 2005) and mangle of practice (Pickering 1995). Some perspectives such as activity theory (Engeström 1999) and distributed cognition (Hutchins 1995; Pea 1993b) have found extensive application in learning and education research. Compared with other treatments of learning, these theories emphasise that all learning practices are both inherently material and social or socio-material (Orlikowski and Scott 2008). Such socio-material configuration or assemblage (Suchman 2007) is a constitutive entanglement that presumes neither independent nor interdependent entities (Barad 2003). Instead, all entities (whether social or technological, human or material) are inseparable. Latour (discussed in Orlikowski and Scott 2008, 455) paints a vibrant picture to capture the essence of socio-materiality. He asks us to imagine a battlefield with soldiers all lined up. He argues that there are no soldiers without their uniforms and arms, they co-constitute each other. Soldiers do not exist, especially on a battlefield, without their essential materials; and the materials, even if lying on the battlefield, are immaterial without the soldiers.

Although not as dramatic as soldiers on the battlefield, a similar picture of socio-materiality can be painted of any learning environment. It is hard to imagine learning taking place without the use of materials. Even before the advent of information technology, books were a central part of learning practices. Other materials such as blackboards are historically more recent but almost as prevalent. But, similar to uniforms and arms lying on the battlefield, these learning tools in and of themselves are neither essential nor sufficient for learning. Yet, most of the prevalent discourse on learning technologies essentially describes the characteristics of tools disembodied from their actual use. Tools and technologies have functions that are expected to lead to certain kinds of learning. On the other hand, alternate discussions of learning focus disproportionately on the social or psychological aspects of learning without bringing into consideration material aspects. Therefore, within the context of learning technology, I argue that socio-materiality can play a critical role by helping us overcome an inherent dualism in the learning technologies literature between the social implications of technology use and the material aspects of technology design; this dualism either privileges the social or the technical while failing to provide proper attention to the socio-material assemblage. 


\section{Socio-materiality and learning technology}

Technology does not exist independent of its use. (LeBaron 2002, 433)

The notion of socio-materiality has not been explored in depth in relation to learning technologies (for a notable exception see Sørensen 2008). It does have some lineage, however, in the learning sciences literature (Johri and Olds 2011) and is most closely related to the ideas of situated learning (Lave and Wenger 1991; Wenger 1998), distributed cognition (Hutchins 1995; Pea 1993b), and activity theory (Engeström 1999). Lave and Wenger specifically called out the problematic relationship with technology evident in research on learning: "In general, social scientists who concern themselves with learning treat technology as a given and are not analytic about its interrelations with other aspects of a community of practice" (1991, 101). They recognised the lack of attention given to the embeddedness of technology within its larger - primarily social - context. The distributed cognition approach (Hutchins 1995; Pea 1993b) tried to address some of these concerns by articulating the importance of the material environment in cognition. Scholars in this tradition argued successfully that cognition is distributed and is accomplished or performed through a combination of artefacts and people working together, and is embedded and cannot be isolated from practice (Hutchins 1995; Pea 1993b; Pea 1994). Although it argues for taking both the social and material into account, distributed cognition theory focuses disproportionally on 'system' that relegates both the material and social within it to the boundary and also pays scant attention to the dynamicity of the distributed system. Therefore, it becomes hard to assess changes in the system overtime since there is a lack of accounting for the role of components. The idea of an assemblage, on the other hand, allows us to take a sociomaterial view to look beyond the dualism of the social and the material without demoting the value of either. A view that incorporates assemblages also provides a way to study adaption over time.

The question that arises next is if we do not look at the material - technological - and social aspects separately, how can we proceed with a socio-material account? The solution, according to Orlikowski and Scott (2008), is through a focus on agencies. Technology/materiality is so omnipresent that it is hard to have a non-material understanding that does justice to actual learning practices. And vice versa, while focusing on technology solely it is hard to include other factors. But the important issue to understand here is that theoretical assemblage does not imply that there can be no analytical distinction between the material and the social; it is important to remember that "Any distinction of humans and technologies is analytical only, and done with the recognition that these entities necessarily entail each other in practice" (Orlikowski and Scott 2008, 456). Given that technology and contemporary learning practices saturate each other, any effort to theorise learning practices must encompass technology in learning environments. In essence, the objective here is to show how artefacts derive their meaning, for both people and their practices, through social agency; and social agency in turn is highly dependent on the material world for its meaning-making. Socio-materiality is not about the material going away, but about encapsulating the meaning of the material, how it matters, in learning practice. The presence of material is less important than how the material is configured in practice and enacted in the moment. The boundaries between the social and the material are constructed in the moment. The material changes as it gets it meaning from practice and this meaning changes as practices change. 
A lens that views learning technology as an assemblage allows for improved understanding of the co-constitutive nature of the socio-cognitive and the material and the building of better theory. Furthermore, a socio-material account provides a robust model that can be applied across a range of technologies and it can help provide a comparative understanding of changes due change in technology; for instance, what changes as a device or system transforms from physical to digital. But for a learning technology theory of socio-materiality that can account for differences in learning practice due to differences in material, we often have to bring analytical focus on the materiality itself - to its affordances - as different materials and their materialities might relate to cognition differently. Sørensen $(2008,92)$ argues, as do others, that as learning technology researchers we have to pay attention to the affordances of materiality even though in an ideal case we will forget that dualism. One way, therefore, to articulate the role of information technology in learning is to show the shifts in assemblages by leveraging different affordances of the material and even of the social, a view that can also be seen, to a lesser degree, in empirical studies of distributed cognition and the discussion of cognitive artefacts (Hutchins 1999; Pea 1993a; Norman 1991).

\section{Socio-material bricolage as an analytical framework}

To demonstrate the application of socio-materiality, I now discuss its application in three research studies I have conducted either alone or with my colleagues and students over the past five years. The primary motivation for these studies was to understand the emergent aspects of learning practices and the elements - social and material - that facilitate these assemblages as well as define them. Towards this end, I leverage socio-materiality and the concept of bricolage (Levi-Strauss 1967) to advance the notion of socio-material bricolage. This conception provides a useful analytical lens to examine the emergent and socially and materially intertwined nature of human practices. Specifically, it focuses on the capacity of users to make use of the tools available to them within a constellation of social practices. This making do with what is available on hand was termed by Levi-Strauss (1967) as bricolage. Levi-Strauss was interested in how people make do with what they have at hand rather than sticking to a planned approach that would require using preexisting tools and practices as opposed to tools that are immediately available. Bricolage is about the particular and the particularities, and in the case of learning technologies it helps explain the relationship between practice-as-designed and practice-as-practiced or emergent. The concept of bricolage shifts focus away from technology design as usually understood as the design of an artefact towards emergent design of technology-in-use, particularly by the users.

The first research study involved the use of pen-based computing, tablet PCs, in large lecture classes (Johri and Lohani 2011). In this action research project we, the instructors, were interested in conceptualising the use of technology within large classes (300 students or more) with the aim to improve student participation. One inherent weakness of large classes is that it is hard to get students involved due to constraints of class size and time available for interaction. We wanted to reflect on our technology use in order to provide the highest learning opportunity for students. The initial conception was not very different than what has existed for over a century - a delivery model. With the tablets we can present slides and write on them making it more attractive. The delivery model was identified as what it was 
(delivery of instruction), and instead a participatory conception was proposed as our view of technology shifted from that of a tool to that of a "tool in socio-cognitive context" or assemblage. The purpose of the socio-material assemblage now was to provide all students the opportunity to participate and to guide their participation. This was accomplished by giving students the opportunity to write digitally on slides and share them with the instructor (and subsequently with the class). The shift, although basic in terms of the use of technology, was significant in terms of pedagogy as it was about creating new learning practices (participatory) that allowed electronic dialoguing (Evans and Johri 2008). This conception was emergent and we modified as we engaged more with the practice that kept changing as new tools and functions became available to us; we had to modify our learning practices and engage in socio-material bricolage. For instance, we introduced multiple-choice questions and problem-solving exercises within the lectures that prompted students to respond by submitting their slides to the instructors. Over time, we made these exercises shorter but more frequent to keep the students engaged. We utilised features in the software that allowed us to poll students - they could submit responses on a multiple choice or submit responses indicating their comprehension of a particular topic that was being discussed. Their responses were instantly visible to us allowing us to respond appropriately.

A second research study examined the use of technology by engineering student teams working on design projects (Pembridge, Johri, and Williams 2009). In this study as well, students were equipped with tablet PCs. Data were collected from student teams over a semester-long design project through recording of meetings and focus groups at the end of the semester. Their design artefacts were also archived and analysed. We performed a comparative analysis of two groups that undertook the design of the same artefact but followed significantly different design practices. One team met face to face for all their design sessions and had a physical assemblage that involved significant use of technology within the same location. The other team enacted a virtual design practice where they used instant messaging (AIM) and tablet PC software called OneNote concurrently to interact as well as to design. This was an emergent practice based on students' needs, they were unable to meet physically outside class, and the practice evolved over the semester. The students experimented with different modalities to develop a learning practice - an assemblage - that would help them overcome barriers to collaboration and accomplish their project. Through our analysis we determined that, for successful outcomes, computational devices and accompanying software need to support two aspects of the design process: representational practices and relational practices. Representational practices include all aspects of creating and transforming representations, such as drawing sketches, writing verbal descriptions, calculating numeric data, and, converting one form of information into another, such as text into sketch. Relational practices refer to interactional aspects of design work, how team members communicate and subsequently collaborate with each other. These two practices are highly intertwined. In face-to-face interaction, representations, gestures and physical movements are all part of the design practice. In technology-mediated settings, particularly in the team we observed, the students created this context by using synchronous chat tool and concurrent OneNote session to share sketches and to work together on a sketch. Over the course of the semester, they evolved their practices - both social and material elements - to produce a better design. Once again, in this study we see socio-material bricolage in action. The students made 
use of the tools at hand and ensured that the social and material was aligned and served each other.

A final empirical example that demonstrates socio-material bricolage comes from a study of geographically distributed software engineers that experimented with different assemblages to develop work practices that were aligned across locations and ensured knowledge sharing within the team (Johri 2011a). New teams were added in international locations and teams were expanded to include team members from other locations, necessitating teamwork across time zones that were as much as 15 hours apart on some occasions. To reacquire their work-life balance, lost due to extensive time zone differences, co-workers actively experimented with different combinations of tools and social coordination mechanisms. Their greatest need was for coordination among team members working on the same problem or piece of the overall software code. In addition, they had to ensure a knowledge ecosystem that facilitated both archival and just-in-time access to expertise. To achieve this, the workers decided to use a combination of lean tools such Internet Relay Chat, audio-conferencing, email, and wikis. They deliberately left out 'rich' media such as video-conferencing due to both material and social constraints. Where video required high bandwidth and synchronous use, lean media that were text-rich afforded the sharing of software code that helped establish common ground and a joint activity space. They ended up developing an assemblage that was a mix of lightweight communication tools such as Internet Relay Chat and company-provided equipment such as the telephone. This assemblage constantly evolved with novel experiments across time. The emergent solutions and the ability to draw on tools at hand to construct new assemblages serve as an illustration of socio-material bricolage. This case, about informal learning at work, highlights other aspects of learning for socio-material bricolage - preferences and attitudes of other co-workers and access to materials. Similar practice creation was also found in another organisation where workers utilised lean media, and excluded email, showcasing socio-material bricolage at the firm level (Johri 2011b).

Although more than one interpretation of the learning practices reported in these studies is possible, a socio-material account makes a distinct contribution by allowing for equal and mutual emphasis of both social and material considerations. In each of these cases, a socially heavy account would miss the role of material affordances and a material account would not be able to represent the social changes accompanying material use, thereby impacting a fair interpretation of the role of learning technologies in learning practices. Furthermore, the notion of bricolage allows us to leverage the 'making do' component of the practice, thereby allowing us to account for the ever important dynamic and evolving component of any practice. Specifically, across the three cases we see a representation of three characteristics of bricolage identified by Baker and Nelson (2005). First, learners and knowledge workers made do - that is, they engaged in action and activity rather than lingering too long over how to create a workable solution. Second, they used the resources at hand to the best of their ability. They stretched the boundaries of what was possible with the resources they had at hand. Even though during the interviews most informants lamented the lack of access to other easy-to-use tools, they went on about their work without those resources. Finally, the informants were able to use existing resources for new purposes. All these instances of bricolage, however, were mediated by materiality and intricately involved the social world whether it was team formation or creation of a participatory learning environment. 
Therefore, socio-material bricolage encapsulates the idea that practices emerge through the ad hoc use of available artefacts by people often in conjunction with others and while participating in situated activities. The usefulness of the concept of socio-material bricolage goes beyond illustrating the emergent nature of assemblages and also helps establish the idiosyncrasies of socio-material relations. It also, rightly, emphasises the idea that particularities will be present and observable across practices, and, practices developed by and within the context of a combination of people and material will not automatically transfer to another scenario; even in slightly different contexts, variations of an assemblage will exist.

\section{Discussion and conclusion}

In this paper I have advanced socio-materiality as a theoretical concept and sociomaterial bricolage as an analytical framework that can assist members of the field of learning technology by guiding both research and practice. Of course, many other epistemological and ontological alternatives exist and can be equally fruitful for the field of learning technology, but as I have argued above a focus on materiality of learning practices provides a unique vantage point from which to advance socio-cognitive understanding by incorporating both materiality and sociality, without privileging either, and by accounting for emergent characteristics of assemblages. I have also argued that to leverage socio-material analytically, it is often necessary to separate the social and the material although in practice - for informants - they are not distinct issues. I have focused on the ensemble but have found it necessary to distinguish between the underlying factors, as only by understanding the emergence of the ensemble - and its parts - can we delve into aspects of learning practices such as the motivation for their inception and subsequent development. Needless to say, socio-materiality applies to all form of learning practices as they are almost universally mediated by materiality. But, by making materiality of learning practices salient, this perspective allows those interested in learning technologies to make the use of technology a useful focus of study without delineating other aspects of the practice to the margins. This is necessary to account fully and in depth for the role of technology in learning practices and to account for nontechnological aspects as well.

Looking back at the discussion on the utility of theory, socio-materiality helps situated research on learning technology within the context of practice-based studies of learning, and in particular as an extension of situated learning and communities of practice framework. Socio-materiality assists us in providing interpretive explanations of learning practices that account for technology contextually. Socio-material accounts require a specific empirical power from data, thereby helping frame research studies from their inception. And finally, through socio-material accounts we can express our findings in useful ways, as exemplified by socio-material bricolage. Furthermore, socio-materiality provides both originality and utility. It advances understanding compared with previous accounts of technology use by providing sufficient and necessary emphasis on both the social and material aspects of learning. For other practical applications, teachers and learners and others who implement or directly use technology for learning can benefit from developing a more holistic understanding of their interactions with technology and from a heightened awareness of how the social and material are intertwined. In this respect, the representation of the principles of activity theory in the form of a triangle has enabled 
easier adoption by the design and user communities (Engeström 1999; Johri 2005). A similar framework for socio-material bricolage in the future can be highly beneficial in reaching different and larger audiences.

\section{Acknowledgements}

The author would like to thank the informants who participated in the studies reported here. The studies were partially funded by the US National Science Foundation Awards 0757540 and 0954034. Any opinions, findings, and conclusions or recommendations expressed in this paper are those of the author(s) and do not necessarily reflect the views of the National Science Foundation.

\section{References}

Baker, T., and R.E. Nelson. 2005. Creating something from nothing: Resource construction through entrepreneurial bricolage. Administrative Science Quarterly 50: 329-66.

Barad, K. 2003. Posthumanist performativity: Toward an understanding of how matter comes to matter. Signs 28, no. 3: 801-31.

Blackler, F. 1995. Knowledge, knowledge work, and organizations: An overview and interpretation. Organization Studies 16: 1021-46.

Bourdieu, P. 1990. The logic of practice. Cambridge: Polity.

Brown, J.S., and P. Duguid. 2001. Knowledge and organization: A social-practice perspective. Organization Science 12, no. 2: 198-215.

Callahan, R.E. 1962. Education and the cult of efficiency. Chicago, IL: Chicago University Press.

Cook, S.D., and J.S. Brown. 1999. Bridging epistemologies: The generative dance between organizational knowledge and organizational knowing. Organization Science 10, no. 4: $381-400$.

de Certeau, M. 1984. The practice of everyday life. Berkeley: University of California Press.

Engeström, Y. 1999. Activity theory and individual and social transformation. In Perspectives on activity theory, 19-38. Cambridge, UK: Cambridge University Press.

ESA. 2010. Essential facts about the computer and video game industry. http://www.theesa. com/facts/pdfs/ESA_Essential_Facts_2010.PDF (accessed June 27, 2011).

Evans, M., and A. Johri. 2008. Facilitating guided participation through mobile technologies. Journal of Computing in Higher Education 20, no. 2: 92-105.

Feldman, M., and W. Orlikowski. 2011. Theorizing practice and practicing theory. Organization Science forthcoming. doi:10.1287/orsc.1100.0612. http://orgsci.journal.informs.org/ content/early/2011/02/23/orsc.1100.0612.

Greeno, J. 2006. Learning in activity. In The Cambridge Handbook of the Learning Sciences, ed. K. Sawyer, 79-96. New York: Cambridge University Press.

Hutchins, E. 1995. Cognition in the wild. Cambridge, MA: MIT Press.

Hutchins, E. 1999. Cognitive artifacts. In The MIT encyclopedia of the cognitive sciences, 126-8. Cambridge, MA: MIT Press.

James, W. 1907. Pragmatism. New York: The American Library.

Johnson, L., R. Smith, H. Willis, A. Levine, and K. Haywood. 2011. The 2011 horizon report. Austin, TX: The New Media Consortium.

Johri, A. 2005. Online, offline, and in-between: Analyzing mediated-action among American and Russian students in an online class. In Computer-supported collaborative learning in higher education, ed. T. Roberts, 259-80. Hershey, PA: IGI Global.

Johri, A. 2010. Creating theoretical insights in engineering education. Journal of Engineering Education 99, no. 3: 183-4.

Johri, A. 2011a. Sociomaterial bricolage: The creation of location-spanning work practices by global software developers. Information and Software Technology 53, no. 9: 955-68.

Johri, A. 2011b. Look ma, no email! Blogs and IRC as primary and preferred communication tools in a distributed firm. Proceedings of the ACM Conference on Computer Supported Cooperative Work, 305-8. New York: ACM Press. 
Johri, A., and V. Lohani. 2011. Framework for improving engineering representational literacy by using pen-based computing. International Journal of Engineering Education 27, no. 5: $958-67$.

Johri, A., and B. M. Olds. 2011. Situated engineering learning: Bridging engineering education research and the learning sciences. Journal of Engineering Education 100, no. 1: $151-85$.

Latour, B. 2005. Reassembling the social: An introduction to actor-network-theory. Oxford: Oxford University Press.

Lave, J. 1988. Cognition in practice: Mind, mathematics and culture in everyday life. Cambridge: Cambridge University Press.

Lave, J., and E. Wenger. 1991. Situated learning: Legitimate peripheral participation. Cambridge: Cambridge University Press.

LeBaron, C.D. 2002. Technology does not exist independent of its use. In CSCL 2: Carrying forward the conversation, ed. T.D. Koschmann, R. Hall, and N. Miyake, 433-38. Mahwah, NJ: Lawrence Erlbaum Publications.

Levi-Strauss, C. 1967. The savage mind. Chicago: University of Chicago Press.

Nielsen. 2010. Led by Facebook, Twitter, global time spent on social media sites up $82 \%$ year over year. http://blog.nielsen.com/nielsenwire/global/led-by-facebook-twitter-globaltime-spent-on-social-media-sites-up-82-year-over-year/ (accessed June 27, 2011).

Norman, D.A. 1991. Cognitive artifacts. Designing interaction: Psychology at the humancomputer interface. New York: Cambridge University Press.

Orlikowski, W. 2002. Knowing in practice. Enacting a collective capability in distributive organizing. Organization Science 13, no. 3: 249-73.

Orlikowski, W.J. 2010. The sociomateriality of organizational life: Considering technology in management research. Cambridge Journal of Economics 34: 125-41.

Orlikowski, W.J., and S.V. Scott. 2008. Sociomateriality: Challenging the separation of technology, work and organization. Annals of the Academy of Management 2, no. 1: 433-74.

Pea, R.D. 1993a. Learning scientific concepts through material and social activities: Conversational analysis meets conceptual change. Educational Psychologist 28, no. 3: 265-77.

Pea, R.D. 1993b. Practices of distributed intelligence and designs for education. In Distributed cognitions, ed. G. Salomon, 47-87. New York: Cambridge University Press.

Pea, R.D. 1994. Seeing what we build together: Distributed multimedia learning environments for transformative communications. Journal of the Learning Sciences 3, no. 3: 285-99.

Pembridge, J., A. Johri, and C. Williams. 2009. Transformative design practices: Comparing face-to-face and technology-mediated design experiences among engineering students. Proceedings of 39th ASEE/IEEE Frontiers in Education Conference, October 8-21, in San Antonio, TX, W2H-1-7. http://fie-conference.org/fie2009/papers/1174.pdf.

Pickering, A. 1995. The mangle of practice. Chicago, IL: University of Chicago Press.

Scanlon, J.J. 1959. The expanding role of television in American education. The Journal of Educational Sociology 32, no. 9: 413-20.

Schatzki, T.R. 2001. Introduction: Practice theory. In The practice turn in contemporary theory, ed. T.R. Schatzki, K.K. Cetina, and E.V. Savigny, 42-55. New York: Routledge.

Sørensen, E. 2008. The materiality of learning. Cambridge: Cambridge University Press.

Suchman, L.A. 2007. Human-machine reconfigurations: Plans and situated actions. Cambridge: Cambridge University Press.

Tyre, M., and E. von Hippel. 1997. The situated nature of adaptive learning in organizations. Organization Science 8: 71-84.

Wenger, E. 1998. Communities of practice: Learning, meaning, and identity. Cambridge: Cambridge University Press. 